\title{
Effect of different volumes of $0.375 \%$ ropivacaine on diaphragmatic paralysis by supraclavicular brachial plexus block under ultrasound guidance
}

\author{
Liangguang Zhang, Rufa Pang, Long Zhang \\ Department of Anesthesiology, Ningbo No. 6 Hospital, Ningbo, China \\ Contributions: (I) Conception and design: L Zhang; (II) Administrative support: L Zhang; (III) Provision of study materials or patients: L Zhang, R \\ Pang; (IV) Collection and assembly of data: L Zhang; (V) Data analysis and interpretation: R Pang; (VI) Manuscript writing: All authors; (VII) Final \\ approval of manuscript: All authors. \\ Correspondence to: Long Zhang. Department of Anesthesiology, Ningbo No. 6 Hospital, 1059\# Zhongshan East Road, Ningbo, China. \\ Email: nblymz@126.com.
}

Background Supraclavicular brachial plexus block (SCBPB) is a traditional anesthesia technique widely
used in upper limb surgery. Ultrasound-guided SCBPB shows the peripheral structure and dynamic local
anesthetic diffusion and can greatly shorten the anesthesia operation time, increase the success rate of
anesthesia, and reduce the incidence of complications. However, it can still block the phrenic nerve and
paralyze the diaphragm, which can be difficult to avoid. This study investigated two different volumes of
the same concentration of ropivacaine used in ultrasound-guided SCBPB, and compared the effects on the
incidence of diaphragmatic paralysis, pulse oxygen saturation ( $\mathrm{SpO}_{2}$ ) and lung function in patients.
Methods: The study group comprised 103 patients who were to undergo surgery on the right forearm or
right hand. They were randomly divided into two groups: group A were given $20 \mathrm{~mL} 0.375 \%$ ropivacaine,
and group B were given 30 mL $0.375 \%$ ropivacaine. We recorded the SpO $\mathrm{O}_{2}$, forced vital capacity (FVC),
and forced expiratory volume in $1 \mathrm{~s}$ (FEV1) before and 30 min after the block, and evaluated whether the
patient had combined respiratory dysfunction according to the lung function indicators. We also recorded
the maintenance time of anesthesia, the recovery time of motor block, and evaluated the effect of anesthesia.
Results: The time to onset of motor block in group B was significantly shorter than in group A (P<0.05).
After 30 min of blockade, the rate of diaphragmatic paralysis in group B under different breathing states was
significantly higher than that of group A (P<0.05); after 30 min of blockade, the rate of partial paralysis of the
diaphragm with forced breathing was significantly higher than the rate of partial paralysis of the diaphragm
with calm breathing (P<0.05).

Conclusions: Both 20 and $30 \mathrm{~mL}$ of $0.375 \%$ ropivacaine can achieve the ideal brachial plexus block with ultrasound-guided SCBPB, but compared with $20 \mathrm{~mL}$ of $0.375 \%$ ropivacaine, $30 \mathrm{~mL}$ of $0.375 \%$ ropivacaine is more likely to cause diaphragmatic paralysis.

Keywords: Diaphragmatic paralysis; dose-response; ropivacaine; supraclavicular brachial plexus block (SCBPB); ultrasound

Submitted Sep 01, 2020. Accepted for publication Nov 03, 2020.

doi: 10.21037/apm-20-1955

View this article at: http://dx.doi.org/10.21037/apm-20-1955 


\section{Introduction}

Supraclavicular brachial plexus block (SCBPB) is a traditional anesthesia technique widely used in upper limb surgery. The key to its success lies in accurate anatomical positioning and uniform diffusion of the anesthetic drug. The traditional brachial plexus block method mainly uses the paresthesia positioning method to locate the nerve, but this can cause nerve damage, pneumothorax, and diffusion of local anesthetic into blood vessels. Even if the upper brachial plexus is blocked with a neurostimulator, the local anesthetic will not be evenly spread, so there is still a considerable failure rate. Ultrasound visualization can display the nerves and surrounding structures in real time, and can guide the puncture needle to enter the target nerve. It can also show the spread of the drug around the nerve after injection, reducing the dosage of local anesthetics and improving the blocking effect $(1,2)$, It has become the gold standard for nerve block (3).

Compared with the traditional blind puncture method, ultrasound-guided SCBPB is intuitive, and enables observation of the surrounding structure of the nerve and the dynamic local anesthetic diffusion. Therefore, it can greatly shorten the anesthesia operation time, improve the anesthesia success rate, extend the duration of the block, and reduce the dosage of anesthetic drug, which will significantly reduce the incidence of local anesthetic poisoning, vascular puncture, pneumothorax, nerve injury and other complications. It is a safer and more effective clinical practice technique (4). However, phrenic nerve block can cause diaphragmatic palsy, and it is still difficult to avoid causing this even with ultrasound-guided SCBPB (5). Diaphragmatic dyskinesia can further lead to decreased ventilation, dyspnea and decreased pulse oxygen saturation $\left(\mathrm{SpO}_{2}\right)$, etc. $(6,7)$, which limits the clinical application of the nerve block and is not conducive to early postoperative recovery. Current research shows that the probability of diaphragmatic paralysis caused by SCBPB is $36-67 \%$ (8). Cornish (9) reported a method of SCBPB whereby a small amount of local anesthetic is injected into the "bottom pocket" and the needle is withdrawn. On the posterolateral side of the brachial plexus, the needle tip with the remaining local anesthetic is injected caudally, and the local anesthetic does not spread to the head or the inside of the subclavian artery, thus avoiding blockage of the phrenic nerve. When the intermuscular sulcus brachial plexus is blocked, $100 \%$ of patients will have ipsilateral diaphragmatic palsy $(5,10,11)$. Ryu et al. (12) confirmed that in $95.7 \%$ of cases of SCBPB, the spread of local anesthetic to the intermuscular groove increases the probability of phrenic nerve block. Studies have also found that reducing the dose of local anesthetic can reduce the incidence of diaphragmatic paralysis (13-16). Research on fixed local anesthetic volume and reduced concentration $(15,16)$, or fixed concentration and reduced volume $(17,18)$ suggests that the low-dose group has a lower incidence of diaphragmatic paralysis, and the lowdose retardation group also has higher respiratory function indexes such as $\mathrm{SpO}_{2}$, forced vital capacity (FVC) and forced expiratory volume in $1 \mathrm{~s}$ (FEV1), but often at the expense of analgesic effect (19). Under the premise of relatively low-dose local anesthetic, there is still a lack of relevant research on the effects of local anesthesia using different concentration and volume combinations on both analgesia and diaphragmatic paralysis.

In this study, we aimed to use the same concentration but two different volumes of ropivacaine to perform ultrasoundguided SCBPB combined with a neurostimulator to compare the effects on the incidence of diaphragmatic paralysis, $\mathrm{SpO}_{2}$ and lung function At the same time, we observed the analgesic effect and other characteristics of brachial plexus block, and explored the effectiveness of ropivacaine, which has less impact on the diaphragm, thus guiding a more clinically rational use of drugs to improve the safety of brachial plexus block.

We present the following article in accordance with the CONSORT reporting checklist (available at http://dx.doi. org/10.21037/apm-20-1955).

\section{Methods}

\section{Subjects}

From November 2018 to November 2019, 103 patients with elective right forearm or right-hand surgery planned to undergo SCBPB under ultrasound guidance at Ningbo No. 6 Hospital. Inclusion criteria were: (I) operative time expected to be $<4$ h, (II) age 18-65 years, (III) body mass index (BMI) $18-30 \mathrm{~kg} / \mathrm{m}^{2}$, (IV) American Academy of Anesthesiologists (ASA) score I or II, and (V) no history of cardiopulmonary dysfunction; conscious, and cooperative; no nerve damage or paresthesia in the affected limb; no contraindications for supraclavicular brachial plexus block.

The exclusion criteria were: (I) $\mathrm{BMI}>30 \mathrm{~kg} / \mathrm{m}^{2}$, (II) arrhythmia, (III) respiratory system disease, (IV) phrenic nerve injury, (V) upper limb sensory or movement disorder, (VI coagulopathy, (VII) severe organ dysfunction, (VIII) 
known allergy to local anesthetics. All patients gave written informed consent.

The study was conducted in accordance with the Declaration of Helsinki (as revised in 2013). The study was approved by Ningbo No. 6 Hospital (No. 20180105) and written informed consent was obtained from all patients.

\section{Research design}

The 103 patients were coded according to the order of admission, and using the envelope method they were randomly assigned by an independent healthcare provider to group A or B at a ratio of 1:1, with 52 cases in group A and 51 cases in group B. $20-25 \mathrm{~mL}$ of ropivacaine is generally accepted in SCBPB under ultrasound guidance (20). Cruvinel et al. (21) confirmed that 20,30, $40 \mathrm{~mL} 0.375 \%$ ropivacaine produced the same anesthesia effect. While Ding et al. (22) studied the effects of different solubility of ropivacaine on diaphragmatic paralysis during acute guided SCBPB, and found that $0.35 \%$ ropivacaine has a good anesthetic effect and has little effect on phrenic nerve function. Pei et al. (23) confirmed that the use of SCBPB with $0.35 \%$ ropcaine $20 \mathrm{~mL}$ can produce a perfect nerve block effect. Therefore, in this experiment, we chose $0.375 \%$ ropercaine $20 \mathrm{~mL}$ and $30 \mathrm{~mL}$ as the research dose. Group A patients were given $20 \mathrm{~mL} 0.375 \%$ ropivacaine, and in group B they were given $30 \mathrm{~mL} 0.375 \%$ ropivacaine. Before the operation, the laboratory staff will distribute anesthetics and the needle tube will be shielded. Both the patients and the anesthetists were unaware of the group assignment.

\section{Preparation before block}

All patients underwent routine fasting and drinking restrictions before operation; no preoperative medication or no oxygen was given. After entering the procedure room, the venous channel was opened, heart rate (HR), blood pressure (BP), and ECG were routinely monitored, and the pulse oxygen saturation $\left(\mathrm{SpO}_{2}\right)$ of the index finger of the patient's contralateral upper limb was recorded.

\section{Diaphragm mobility monitoring}

An independent evaluator, who did not know the group allocation, used ultrasound to observe the normal movement of the diaphragm on the side of the patient's affected limb. With the patient in a supine position, breathing calmly, using the American Terson 3000 ultrasound system (3-5-MHz low-frequency ultrasound probe; Sonos, USA), placing the ultrasound probe at the midpoint of the intersection of the patient's right clavicle, right anterior axillary line and right costal margin. At this position, the direction of the probe points to the head, and the right lobe of the liver is the acoustic window. The probe is adjusted to find the position of maximum diaphragmatic movement. Using $M$-mode, the sampling line is perpendicular to the diaphragmatic muscle line, and three stable waveforms are obtained to separately freeze and measure the movement of each waveform. The average is recorded $(24,25)$. The patient is then instructed to breathe hard, three waveforms are measured in the same way and the maximum value is recorded. At $30 \mathrm{~min}$ after SCBPB injection, the movement of the diaphragm under calm and forced breathing is measured and recorded, and the rate of diaphragm paralysis is calculated (compared with before anesthesia, a decrease in diaphragmatic movement $\leq 25 \%$ means normal diaphragmatic function; between $25-75 \%$ decrease in diaphragmatic movement suggests partial paralysis; reduction of diaphragm mobility by $\geq 75 \%$, nonmovement or paradoxical movement of the diaphragm is complete paralysis of the diaphragm).

\section{$S C B P B$}

The patient is in the supine position with the head tilted to the healthy side by $30^{\circ}$. Routine skin disinfection is performed before connecting the nerve stimulator. An ultrasound system (SonoSite M-Turbo, USA) equipped with a $6-13-\mathrm{MHz}$ high-frequency linear probe locates the midclavicle point, then the subclavian artery and obtains a clear cross-sectional image of the brachial plexus. Color Doppler is used to observe the blood vessels around the brachial plexus and to avoid them during the nerve block. Using in-plane technique to guide the $22 \mathrm{G}$ nerve stimulation needle (B/Braun, Germany) into the "bottom pocket" (where the first rib connects to the subclavian artery), and simultaneously give $1 \mathrm{~mA}$ current stimulation, adjusting the position of the needle tip until the patient's upper extremity convulses. Fine-tune the nerve stimulation needle to reduce the current to $0.3-0.5 \mathrm{~mA}$. When the patient's upper limb is no long convulsing, inject some of the local anesthetic, and then adjust the needle tip position to the nerves. Inject the remaining local anesthetic when the patient reports no tingling, or other uncomfortable, and adjust the direction of the needle tip appropriately through the direction of the liquid diffusion displayed on ultrasound. The operator was 
unaware of the grouping of the patients.

\section{Lung function assessment}

An evaluator who did not know the test group performed the follow-up evaluation before and after the block, and recorded SpO2, FVC, and FEV1 before and $30 \mathrm{~min}$ after the block. FVC and FEV1 were evaluated with a portable pulmonary function tester (Japan CHEST Company, 25-11, 3-chome, Bunkyo, Tokyo). The test was repeated three times and the best value was recorded. Pulmonary function indicators to assess whether the patient had respiratory dysfunction were FEV1/FVC $<70 \%$ and FEV1 $<80 \%$, defined as respiratory dysfunction and subdivided into four degrees of severity, (I) mild: FEV1/FVC $<70 \%$ or FEV1 $\geq 80 \%$; (II) moderate: FEV1/FVC $<70 \%$ or $50 \% \leq \mathrm{FEV} 1$ $<80 \%$; (III) severe: FEV1/FVC $<70 \%$ or $30 \% \leq \mathrm{FEV} 1$ $<50 \%$; (IV) extremely severe: FEV $1<70 \%$ or FEV $1<30 \%$.

The pain block effect test was performed 15 and $30 \mathrm{~min}$ after the injection, and acupuncture was used to record the onset time of the block (C5-6 begin to appear hypoanalgesic) and the block completion time (C5-T1 all nerve segments are blocked). The skin test points selected were: C5: the lower end of the deltoid muscle; C6: the radial side of the lower end of the forearm; C7: the back of the hand between index finger and middle finger between the fingers; C8: the back of the hand between the ring finger and the little finger; T1: the upper inner end of the forearm. The degree of blocking described as ineffective (feels normal), effective (there is touch sensation but pain disappears), or perfect (both touch and pain sensations have disappeared); both effective and perfect indicated that the block was is effective. If there was not complete sensory block within $30 \mathrm{~min}$, it is considered a failure and the patient was excluded from the study).

Other measurement were the duration of sensory block (the time from the end of the block to pain on incision of the patient) and the duration of the motor block (the time from the end of the injection to a mobile shoulder); concurrent anesthesia effect evaluation: excellent, no pain at all; good, only mild pain, the patient can tolerate it, if appropriate, additional small doses of sedation and analgesics (midazolam, fentanyl or remifentanil) can complete the operation; poor: obvious pain, need to change the anesthetic. At the same time, we observed whether there were complications such as puncture of the subclavian artery, local anesthetic poisoning, Horner syndrome, decrease in $\mathrm{SpO}_{2}$, dyspnea, pneumothorax, postoperative upper limb sensation and movement abnormalities.

\section{Postoperative analgesia evaluation}

Parecoxib $40 \mathrm{mg}$ was intravenously administered twice daily for postoperative analgesia within $48 \mathrm{~h}$ after operation. If the patient complained of pain, meperidine $50 \mathrm{mg}$ in addition was administered as a remedial analgesic measure. After returning to the ward, and 4, 8, and $24 \mathrm{~h}$ after anesthesia block, the patient was evaluated for resting pain with the Numerical Pain Rating Scale (NRPS) (0-10 points. 0 points $=$ no pain, 10 points $=$ severe pain). The patient was asked about the timing of first pain within $24 \mathrm{~h}$, whether other remedial analgesia was needed, sleep quality (whether the pain affected falling asleep or waking up on the night after the operation), and satisfaction with arm nerve block $(0-10$ points, 0 points $=$ worst, 10 points $=$ very satisfied $)$.

\section{Statistical analysis}

SPSS (V.22.0; SPSS Inc., Chicago, ILL, USA) was used for statistical analysis of all data. The Kolmogorov-Smirnov test was used for continuous variables to evaluate whether the distribution was normal. Normally distributed measurement data use $\bar{x} \pm \mathrm{s}$ to indicate that the comparison between groups adopts the independent sample test. Non-normally distributed measurement data are represented by $\mathrm{M}$ (P25P75), and comparison between groups was performed by the Wilcoxon rank sum test. Categorical variables are represented by examples (\%), and the Pearson $\chi^{2}$ test was used for comparison between groups. $\mathrm{P}<0.05$ means the difference is statistically significant.

\section{Results}

\section{General clinical data}

There was no statistical difference between the two groups of patients in height, weight, age, sex and general preoperative clinical data (HR, BP, ECG, $\mathrm{SpO}_{2}$ ). There was no significant difference in lung function (FEV1/FVC) or the degree of diaphragmatic movement before the block (Table 1).

\section{Pain and motor blocking effects}

The onset time of pain block and motor block in group B was significantly shorter than in group $A(P<0.05)$. There 
Table 1 Baseline demographic and clinical characteristics of the study population

\begin{tabular}{lccc}
\hline Variables & Group A $(\mathrm{n}=50)$ & Group B $(\mathrm{n}=50)$ & P value \\
\hline Age (years) & $43.62 \pm 7.66$ & $44.74 \pm 7.71$ & 0.445 \\
Weight $(\mathrm{kg})$ & $64.96 \pm 9.17$ & $65.16 \pm 7.42$ & 0.905 \\
Height $(\mathrm{cm})$ & $166.84 \pm 6.74$ & $165.28 \pm 6.47$ & 0.24 \\
Sex (F/M) & $20 / 30$ & $18 / 32$ & 0.068 \\
BMI (kg/m $\left.{ }^{2}\right)$ & $23.23 \pm 2.07$ & $23.78 \pm 1.56$ & 0.135 \\
ASA physical & $12 / 38$ & $9 / 41$ & 0.461 \\
status (l/II) & & & \\
SpO $(\%)$ & $97.05 \pm 1.97$ & $96.64 \pm 1.79$ & 0.258 \\
FEV1/FVC (\%) & $85.78 \pm 2.92$ & $86.64 \pm 3.02$ & 0.152 \\
\hline
\end{tabular}

FEV1, forced expiratory volume in $1 \mathrm{~s}$; FVC, forced vital capacity; $\mathrm{SpO}_{2}$, pulse oxygen saturation.

was no significant difference in the duration of pain block and motor block between the two groups $(\mathrm{P}>0.05)$ (Table 2).

\section{Lung function}

The FEV1/FVC of both group A and group B decreased after $30 \mathrm{~min}$ of resistance lag. Compared with before the block, the lung function FEV1/FVC of group B decreased more than that of group A after 30 min of block, but the difference was not statistically significant (Table 3).

\section{Diaphragmatic paralysis}

After 30 min of blockade, the rate of diaphragmatic paralysis in group B under different breathing states was significantly higher than that of group $\mathrm{A}(\mathrm{P}<0.05)$; compared with calm breathing, the rate of partial diaphragmatic paralysis in the two groups significantly increased when breathing hard after 30 min of blockade $(\mathrm{P}<0.05)$ (Tables 4,5$)$.

\section{Anesthesia effect}

Two patients in group A and one patient in group B were changed to general anesthesia due to block failure; their data were excluded. At 15 and $30 \mathrm{~min}$ after the injection, the number of patients with complete pain sensation in each nerve root increased over time. There were 5 and 3 patients in group A and B, respectively, with fentanyl. There was no significant difference in anesthesia effect between the two groups (Table 6). After returning to the ward, the NRPS of the patients was evaluated 4,8 , and $24 \mathrm{~h}$ after blockade, and the time when pain first appeared was recorded. There was no statistical significance between the two groups. There were $5(10 \%)$ patients in group A and $3(6 \%)$ in group B who had effects on sleep effects. There was no statistical significance between the two groups. The anesthesia satisfaction of the two groups was not statistically significant (Table 7).

\section{Complications}

Three patients in group B experienced transient dyspnea and decreased oxygen saturation, but it was not statistically significant.

\section{Discussion}

Because the diaphragm provides more than $70 \%$ of the inspiratory power, paralysis will directly affect respiratory function. When breathing calmly, movement of the diaphragm of $1-2 \mathrm{~cm}$ can provide $75 \%$ resting lung ventilation; when forced breathing, the range of movement of the diaphragm can reach $7-11 \mathrm{~cm}$. Although paralysis of one side of the diaphragm caused by brachial plexus block has no obvious clinical symptoms in most patients, those with respiratory disease, severe heart disease, diabetes with peripheral neuropathy, or obesity will experience chest tightness and difficulty breathing. In addition, obese patients suffer from respiratory distress due to reduced respiratory reserve and intolerance of transient diaphragmatic paralysis. Guirguis et al. (26) reported a case of acute respiratory failure in an obese patient treated with $0.5 \%$ ropivacaine $12.5 \mathrm{~mL}$ and $1 \%$ mepivacaine $12.5 \mathrm{~mL}$ for SCBPB. Acute respiratory failure occurred, requiring emergency intubation to relive the symptoms. Therefore, for such patients, we need to choose a dose of local anesthetic that has little effect on the diaphragm. Unilateral diaphragmatic paralysis reduces vital capacity by $30 \%$ and ventilation by $20 \%$. However, due to compensatory effects, most patients are often asymptomatic, but a small number of patients may experience sleep hypopnea, recurrent lung infections, restricted movement, shallow rapid breathing, and On PHYSICAL examination, abnormal inward movement of the abdomen may be found (21).

Ryu et al. (12) reported on SCBPB with administration of $25 \mathrm{~mL}$ of local anesthetic. The spread of local anesthetic to the intermuscular groove in $95.7 \%$ of patients increased the probability of phrenic nerve block. Therefore, the dose 
Table 2 Comparison of onset time and duration of sensory block and motor block between the two groups (min, $\bar{x} \pm \mathrm{s}$ )

\begin{tabular}{lccccc}
\hline Group & $\mathrm{n}$ & Onset time of pain block & Onset time of moto block & Duration of pain block & Duration of motor block \\
\hline A & 50 & $6.32 \pm 1.99$ & $8.54 \pm 1.74$ & $643.14 \pm 100.37$ & $577.08 \pm 100.62$ \\
B & 50 & $5.56 \pm 1.65^{\mathrm{a}}$ & $5.70 \pm 1.28^{\mathrm{a}}$ & $664.06 \pm 94.20$ & $599.50 \pm 96.82$ \\
\hline
\end{tabular}

Compared with group $A,{ }^{\mathrm{a}} \mathrm{P}<0.05$.

Table 3 Comparison of pulmonary function between the two groups before and $30 \mathrm{~min}$ after nerve block $(\bar{x} \pm \mathrm{s}, \%)$

\begin{tabular}{lccc}
\hline \multirow{2}{*}{ Group } & \multirow{2}{*}{$\mathrm{n}$} & \multicolumn{2}{c}{ FEV1/FVC } \\
\cline { 3 - 4 } & & Before block & 30 min after block \\
\hline $\mathrm{A}$ & 50 & $85.78 \pm 2.92$ & $80.20 \pm 3.78$ \\
$\mathrm{~B}$ & 50 & $86.64 \pm 3.02$ & $81.46 \pm 3.82$ \\
$\mathrm{t}$ value & & 1.445 & 0.152 \\
$\mathrm{P}$ value & & 1.658 & 0.121 \\
\hline
\end{tabular}

FEV1, forced expiratory volume in $1 \mathrm{~s}$; FVC, forced vital capacity.

Table 4 Comparison of diaphragmatic activity in different breathing states before and $30 \mathrm{~min}$ after nerve block $(\bar{x} \pm \mathrm{s}, \mathrm{cm})$

\begin{tabular}{lccc}
\hline Group & $\mathrm{n}$ & Before block & 30 min after block \\
\hline A & 50 & & \\
Calm breathing & & $1.87 \pm 0.42$ & $1.06 \pm 0.55^{\mathrm{a}, \mathrm{b}}$ \\
Forced breathing & & $5.55 \pm 0.90$ & $3.75 \pm 1.20^{\mathrm{a}, \mathrm{b}}$ \\
B & 50 & & \\
Calm breathing & & $1.93 \pm 0.46$ & $0.68 \pm 0.52$ \\
Forced breathing & & $5.39 \pm 0.87$ & $3.04 \pm 1.31$ \\
\hline
\end{tabular}

${ }^{a}$ Comparison in the same group, $\mathrm{P}<0.05$; ${ }^{b}$ comparison between groups, $\mathrm{P}<0.05$.

Table 5 Comparison of diaphragmatic paralysis in the two groups under different respiratory states after 30 min of blockade (n, \%)

\begin{tabular}{lccccc}
\hline \multirow{2}{*}{$\begin{array}{l}\text { Breathing } \\
\text { state }\end{array}$} & Group & $\mathrm{n}$ & \multicolumn{2}{c}{ Degree of paralysis } & \begin{tabular}{c} 
Total \\
\cline { 4 - 5 } Calm
\end{tabular} \\
\cline { 5 - 6 } & $\mathrm{A}$ & 50 & $9(18)$ & $17(34)$ & $26(52)$ \\
& B & 50 & $8(16)$ & $31(62)$ & $39(78)^{\mathrm{a}}$ \\
Forced & $\mathrm{A}$ & 50 & $17(34)^{\mathrm{b}}$ & $5(10)$ & $22(44)$ \\
& B & 50 & $23(46)^{\mathrm{b}}$ & $9(18)$ & $32(64)$ \\
\hline
\end{tabular}

Compared with group $\mathrm{A},{ }^{\mathrm{a}} \mathrm{P}<0.05$; compared with calm breathing, ${ }^{\mathrm{b}} \mathrm{P}<0.05$.
Table 6 Comparison of the two groups with sensory blockade after drug injection (n, \%)

\begin{tabular}{lccll}
\hline Nerve & Group & $\mathrm{n}$ & $15 \mathrm{~min}$ & $30 \mathrm{~min}$ \\
\hline C5 & A & 50 & $50(100)$ & $50(100)$ \\
C6 & B & 50 & $50(100)^{\mathrm{a}}$ & $50(100)^{\mathrm{a}}$ \\
& A & 50 & $50(100)$ & $50(100)$ \\
C7 & B & 50 & $50(100)^{\mathrm{a}}$ & $50(100)^{\mathrm{a}}$ \\
& A & 50 & $41(82)$ & $49(98)$ \\
C8 & B & 50 & $43(86)^{\mathrm{a}}$ & $50(100)^{\mathrm{a}}$ \\
& A & 50 & $36(72)$ & $40(80)$ \\
T1 & B & 50 & $39(78)^{\mathrm{a}}$ & $43(86)^{\mathrm{a}}$ \\
& A & 50 & $37(74)$ & $44(88)$ \\
\hline
\end{tabular}

Compared with group $A,{ }^{\mathrm{a}} \mathrm{P}>0.05$.

and volume of local anesthetic are the key to the success of brachial plexus block. In addition, the occurrence of complications must be minimized while paying attention to the success of the block. The phrenic nerve and brachial plexus are within $2 \mathrm{~mm}$ of each other at the cricoid cartilage level, and below the cricoid cartilage level, the occurrence of phrenic nerve block is volume-dependent, and reducing the volume of local anesthetic can reduce the incidence of phrenic nerve block (27). Studies show that the minimum effective volume of local anesthetic for SCBPB is $32 \mathrm{~mL}$ (28), but $20 \mathrm{~mL}$ of $0.375 \%$ ropivacaine for SCBPB can produce a perfect nerve block effect (23). Ding et al. (22) studied the effects of different concentrations of ropivacaine on diaphragmatic paralysis during ultrasound-guided SCBPB and found that $0.375 \%$ ropivacaine had a good anesthesia effect and little effect on phrenic nerve function.

The present study was a prospective, randomized, double-blind, parallel-controlled clinical study. The results showed that for SCBPB used for intraoperative and postoperative analgesia of right forearm or right-hand 
Table 7 Comparison of analgesia between the two groups

\begin{tabular}{|c|c|c|c|c|c|c|c|c|}
\hline Group & $n$ & \multicolumn{4}{|c|}{ NRPS [M (P25-P75)] } & $\begin{array}{l}\text { Time of first } \\
\text { pain }(h)\left(\bar{x}_{ \pm s}\right)\end{array}$ & $\begin{array}{l}\text { Effect on falling asleep } \\
\text { or waking up, } \mathrm{n}(\%)\end{array}$ & $\begin{array}{l}\text { Satisfaction } \\
\text { score }\left(\bar{x}_{ \pm s}\right)\end{array}$ \\
\hline B & 50 & $0(0-0)$ & $0(0-0)$ & $0(0-0)$ & $3(2-3)$ & $11.07 \pm 1.57$ & $3(6 \%)$ & $9.58 \pm 0.76$ \\
\hline Statistics & & $Z=0.000$ & $Z=-0.000$ & $Z=-0.583$ & $Z=-1.163$ & $t=1.075$ & $\chi^{2}=0.543$ & $t=0.625$ \\
\hline
\end{tabular}

surgery, the same concentration of ropivacaine $(0.375 \%)$ in either 20 or $30 \mathrm{~mL}$ caused no statistically significant difference in diaphragmatic paralysis, decreased pulse oxygen saturation, changes in respiratory function, and analgesia. The incidence of diaphragmatic paralysis and the changes in lung function in this study were similar to the results of previous studies $(16,29)$. The $0.375 \%$ ropivacaine $30 \mathrm{~mL}$ group had a greater lung function reduction than the $20 \mathrm{~mL}$ group. Although the incidence of diaphragmatic paralysis was nearly $80 \%$, no patients complained of dyspnea or severely decreased oxygen saturation. This may be related to several factors. Firstly, a relatively low dose of local anesthetic of only $112.5 \mathrm{mg}$ was used. Secondly, patients with severe lung bronchial disease, ASA $\geq$ grade III, and $\mathrm{BMI} \geq 32$ were not included in the trial. In addition, the patients were relatively young, with an average age of 45 years or less.

\section{Study limitations}

This study did not include patients with respiratory or circulatory diseases or obese patients, so it is not clear how diaphragmatic muscle paralysis occurs in these patients after SCBPB. Because the two groups of local anesthetics have different capacities, brachial plexus block operators were not blinded. The double-blind settings in the study were for grouping: patients were blind and follow-up evaluators were blind. However, in addition to pain assessment, ultrasound observation of diaphragmatic movement, lung function testing and other indicators were relatively objective, which may affect the effect of blinding.

In summary, SCBPB with $0.375 \%$ ropivacaine $20 \mathrm{~mL}$ and $0.375 \%$ ropivacaine $30 \mathrm{~mL}$ under ultrasound guidance can obtain satisfactory anesthesia effects. At the same concentration, a small volume of local anesthetics has a low rate of diaphragmatic paralysis, and $0.375 \%$ ropivacaine
$20 \mathrm{~mL}$ caused less diaphragmatic paralysis, which makes it suitable for clinical application.

\section{Acknowledgments}

Funding: The second batch of agriculture and social development in Yinzhou District in the 2019 Science and Technology Project (Yinke [2019] 87).

\section{Footnote}

Reporting Checklist: The authors have completed the CONSORT reporting checklist. Available at http://dx.doi. org/10.21037/apm-20-1955

Data Sharing Statement: Available at http://dx.doi. org/10.21037/apm-20-1955

Conflicts of Interest: All authors have completed the ICMJE uniform disclosure form (available at http://dx.doi. org/10.21037/apm-20-1955). The authors have no conflicts of interest to declare.

Ethical Statement: The authors are accountable for all aspects of the work in ensuring that questions related to the accuracy or integrity of any part of the work are appropriately investigated and resolved. The study was conducted in accordance with the Declaration of Helsinki (as revised in 2013). The study was approved by Ningbo No. 6 Hospital (No. 20180105) and written informed consent was obtained from all patients.

Open Access Statement: This is an Open Access article distributed in accordance with the Creative Commons Attribution-NonCommercial-NoDerivs 4.0 International License (CC BY-NC-ND 4.0), which permits the non- 
commercial replication and distribution of the article with the strict proviso that no changes or edits are made and the original work is properly cited (including links to both the formal publication through the relevant DOI and the license). See: https://creativecommons.org/licenses/by-nc-nd/4.0/.

\section{References}

1. McNaught A, Shastri U, Carmichael N, et al. Ultrasound reduces the minimum effective local anaesthetic volume compared with peripheral nerve stimulation for interscalene block. Br J Anaesth 2011;106:124-30.

2. Qin Q, Yang D, Xie H, et al. Ultrasound guidance improves the success rate of axillary plexus block: a metaanalysis. Braz J Anesthesiol 2016;66:115-9.

3. Neal JM. Ultrasound-guided regional anesthesia and patient safety: update of an evidence-based analysis. Reg Anesth Pain Med 2016;41:195-204.

4. ZC. Clinical observation of cervical brachial plexus combined block anesthesia for clavicle fracture surgery. Modern Chinese Doctor 2008;46:112-20.

5. Urmey WF, Talts KH, Sharrock NE. One hundred percent incidence of hemidiaphragmatic paresis associated with interscalene brachial plexus anesthesia as diagnosed by ultrasonography. Anesth Analg 1991;72:498-503.

6. Jules-Elysee K, Reid SC, Kahn RL, et al. Prolonged diaphragm dysfunction after interscalene brachial plexus block and shoulder surgery: a prospective observational pilot study. Br J Anaesth 2014;112:950-1.

7. Bu J, Li N, Huang X, et al. Feasibility of fast-track surgery in elderly patients with gastric cancer. J Gastrointest Surg 2015;19:1391-8.

8. Marhofer P, Harrop-Griffiths W, Willschke H, et al. Fifteen years of ultrasound guidance in regional anaesthesia: Part 2-recent developments in block techniques. Br J Anaesth 2010;104:673-83.

9. Cornish P. Supraclavicular blocks and phrenic nerve paresis. Reg Anesth Pain Med 2010;35:473; author reply 473-4.

10. Urmey WF, McDonald M. Hemidiaphragmatic paresis during interscalene brachial plexus block: effects on pulmonary function and chest wall mechanics Anesth Analg 1992;74:352-7.

11. Chappell D, Jacob M. Influence of non-ventilatory options on postoperative outcome. Best Pract Res Clin Anaesthesiol 2010;24:267-81.

12. Ryu T, Kil BT, Kim JH. Comparison Between ultrasoundguided supraclavicular and interscalene brachial plexus blocks in patients undergoing arthroscopic shoulder surgery: a prospective, randomized, parallel study. Medicine (Baltimore) 2015;94:e1726.

13. Riazi S, Carmichael N, Awad I, et al. Effect of local anaesthetic volume (20 vs $5 \mathrm{ml}$ ) on the efficacy and respiratory consequences of ultrasound-guided interscalene brachial plexus block. Br J Anaesth 2008;101:549-56.

14. Lee JH, Cho SH, Kim SH, et al. Ropivacaine for ultrasound-guided interscalene block: $5 \mathrm{ml}$ provides similar analgesia but less phrenic nerve paralysis than $10 \mathrm{ml}$. Can J Anaesth 2011;58:1001-6.

15. al-Kaisy AA, Chan VW, Perlas A. Respiratory effects of low-dose bupivacaine interscalene block. Br J Anaesth 1999;82:217-20.

16. Thackeray EM, Swenson JD, Gertsch MC, et al. Diaphragm function after interscalene brachial plexus block: a double-blind, randomized comparison of $0.25 \%$ and $0.125 \%$ bupivacaine. J Shoulder Elbow Surg 2013;22:381-6.

17. Riazi S, Carmichael N, Awad I, et al. Effect of local anaesthetic volume (20 vs $5 \mathrm{ml}$ ) on the efficacy and respiratory consequences of ultrasound-guided interscalene brachial plexus block. Br J Anaesth 2008;101:549-56.

18. Lee JH, Cho SH, Kim SH, et al. Ropivacaine for ultrasound-guided interscalene block: $5 \mathrm{ml}$ provides similar analgesia but less phrenic nerve paralysis than $10 \mathrm{ml}$. Can J Anaesth 2011;58:1001-6.

19. Zhai W, Wang X, Rong Y, et al. Effects of a fixed low-dose ropivacaine with different volume and concentrations on interscalene brachial plexus block: a randomized controlled trial. BMC Anesthesiol 2016;16:80.

20. Vermeylen K, Engelen S, Sermeus L, et al. Supraclavicular brachial plexus blocks: Review and current practice. Acta Anaesthesiol Belg 2012;63:15-21.

21. Cruvinel MG, Castro CH, Silva YP, et al. A comparative study on the postoperative analgesic efficacy of 20,30, or $40 \mathrm{~mL}$ of ropivacaine in posterior brachial plexus block. Rev Bras Anestesiol 2007;57:500-13.

22. Ding Cl. The effect of different concentrations of ropacaine on diaphragmatic muscle mobility during ultrasound-guided supraclavicular brachial plexus block. Zhejiang Medical Science 2013;35:2103-2106.26.

23. Pei Q, Yang Y, Liu Q, et al. Lack of sex difference in minimum local analgesic concentration of ropivacaine for ultrasound-guided supraclavicular brachial plexus block. Med Sci Monit 2015;21: 3459-3466.25

24. He W, Xu Y. Ultrasound assessment of diaphragm mobility by three different approaches in ventilated patients. 
Zhonghua Wei Zhong Bing Ji Jiu Yi Xue 2014;26:914-6.

25. Testa A, Soldati G, Giannuzzi R, et al. Ultrasound M-mode assessment of diaphragmatic kinetics by anterior transverse scanning in healthy subjects. Ultrasound Med Biol 2011;37:44-52.

26. Guirguis M, Karroum R, Abd-Elsayed AA, et al. Acute respiratory distress following ultrasound-guided supraclavicular block. Ochsner J 2012;12:159-62.

27. Kessler J, Schafhalter-Zoppoth I, Gray AT. An ultrasound study of the phrenic nerve in the posterior cervical triangle: Implications for the interscalene brachial plexus block. Reg Anesth Pain Med 2008;33:545-50.

Cite this article as: Zhang L, Pang R, Zhang L. Effect of different volumes of $0.375 \%$ ropivacaine on diaphragmatic paralysis by supraclavicular brachial plexus block under ultrasound guidance. Ann Palliat Med 2020;9(6):3993-4001. doi: 10.21037/apm-20-1955
28. Tran DQ, Dugani S, Correa JA, et al. Minimum effective volume of lidocaine for ultrasound-guided supraclavicular block. Reg Anesth Pain Med 2011;36:466-9.

29. Sinha SK, Abrams JH, Barnett JT, et al. Decreasing the local anesthetic volume from 20 to $10 \mathrm{ml}$ for ultrasoundguided interscalene block at the cricoid level does not reduce the incidence of hemidiaphragmatic paresis. Reg Anesth Pain Med 2011;36:17-20.

(English Language Editor: K. Brown) 